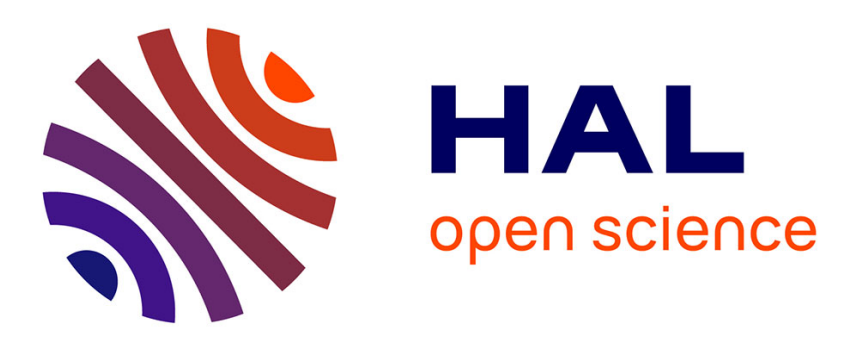

\title{
Nonionic polyoxazoline surfactants based on renewable source: Synthesis, surface and bulk properties
} Chloé Giardi, Vincent Lapinte, Clarence Charnay, Jean Jacques Robin

\section{To cite this version:}

Chloé Giardi, Vincent Lapinte, Clarence Charnay, Jean Jacques Robin. Nonionic polyoxazoline surfactants based on renewable source: Synthesis, surface and bulk properties. Reactive and Functional Polymers, 2009, 69, pp.643-649. 10.1016/j.reactfunctpolym.2009.04.008 . hal-00379102

\section{HAL Id: hal-00379102 https://hal.science/hal-00379102}

Submitted on 27 Apr 2009

HAL is a multi-disciplinary open access archive for the deposit and dissemination of scientific research documents, whether they are published or not. The documents may come from teaching and research institutions in France or abroad, or from public or private research centers.
L'archive ouverte pluridisciplinaire HAL, est destinée au dépôt et à la diffusion de documents scientifiques de niveau recherche, publiés ou non, émanant des établissements d'enseignement et de recherche français ou étrangers, des laboratoires publics ou privés. 


\title{
Nonionic polyoxazoline surfactants based on renewable source: Synthesis, surface and bulk properties
}

\author{
Chloé Giardi, ${ }^{1}$ Vincent Lapinte, ${ }^{1}$ Clarence Charnay, ${ }^{2}$ Jean Jacques Robin ${ }^{1 *}$ \\ ${ }^{1}$ Institut Charles Gerhardt Montpellier UMR5253 CNRS-UM2-ENSCM-UM1 - Equipe Ingénierie et \\ Architectures Macromoléculaires, Université Montpellier II - Bat 17 - cc1702, Place Eugène Bataillon \\ 34095 Montpellier Cedex 5, France \\ ${ }^{2}$ Institut Charles Gerhardt Montpellier UMR5253 CNRS-UM2-ENSCM-UM1 - AIME (Agrégats, \\ Interfaces et Matériaux pour l'Energie), Université Montpellier II - Bat 15 - cc015, Place Eugène \\ Bataillon, 34095 Montpellier Cedex 5, France
}

*CORRESPONDING AUTHOR: Jean-Jacques.Robin@univ-montp2.fr,

Tel: +33467144157, Fax: +33467144028

\begin{abstract}
The synthesis of amphiphilic lipid-polyoxazoline based on copolymers $\left(\mathbf{C O}-\mathbf{P O} \mathbf{x}_{\mathbf{n}}\right)$ with narrow distribution has been achieved via cationic ring-opening polymerization of 2-methyl-2-oxazoline (MOx). Lipid-macroinitiator (COTs) was obtained from commercial castor oil (CO), widely renewable agricultural resource. CO-POx $\mathbf{x}_{\mathbf{n}}$ with various length segments were synthesized from a macroinitiator COTs in order to investigate the effect of the length of the hydrophilic segment on the solution behavior of the nonionic polymer surfactants $\mathbf{C O - P O x _ { \mathbf { n } } . ~ T h e ~ r e s u l t s ~ s h o w e d ~ t h a t ~ t h e ~ c r i t i c a l ~ m i c e l l e ~}$ concentration rised with the increase of POx content and inversely surface tension decreased. The average size of aggregates of these structures suggested the formation of vesicles or nonspherical micelles. Star-shaped morphology of CO-POx $\mathbf{x}_{\mathbf{n}}$ in solid state has also been observed using
\end{abstract}


environmental scanning electron microscopy (ESEM). Addionally energy dispersive X-ray (EDX) analysis demonstrated the presence of POx block in the concentric stripes of the texture.

\section{Keywords}

Castor oil; lipopolymer; nonionic surfactant; self-organisation; polyoxazoline. 


\section{Introduction}

The interest in designing highly specialised synthetic surfactants incorporating blocks coming from renewable resources has increased remarkably during the last few years. Many surfactants are made of natural building blocks like amino acids, sugars and fatty acids. Their low toxicity, good biocompatibility and fast biodegradation are the main reasons for the increasing industrial interest in these compounds. The most important applications for the surfactants are related to their selforganisation in solution. Self-organisation leads to the formation of micelles, liposomes or lyotropic liquid crystalline phases which can be used for the solubilisation of chemicals such as drug carriers or detergents. The preparation of surfactants from renewable sources such as natural oil-based materials and more specifically triglyceride oils have been used for the production of coatings, inks, plasticizers, lubricants and agrochemicals. Among vegetable oils, castor oil (CO) represents a promising raw material due to its low cost, low toxicity, and its availability as a renewable agricultural resource. CO contains ricinoleic acid (12-hydroxy-cis-9-octadecenoic acid) combining hydroxyl groups and unsaturations [1]. From this starting material and water-soluble polymer, amphiphilic surfactants could be designed. Among numerous water-soluble polymers, polyoxazolines (POx)s are attractive for their low acute toxicity $[2,3]$ and have been approved by US Food and Drug Administration (FDA). (POx)s have recently emergered in surface chemistry and biomaterials science where they act for instance as nonionic surfactants and could be compared with commercial nonionic polymer ones: Pluronics ${ }^{\circledR}$ [4] and analogous PEO based surfactants [5].

Some polyoxazoline surfactants have already been mentioned in the literature with various macromolecular architectures. Amphiphilic block copolymers were synthesized between 2-methyl- or 2ethyl-2-oxazoline and 2-alkyl-2-oxazoline where the long alkyl chain afforded a hydrophobic character $[4,6,7]$. Other amphiphilic polyoxazolines were prepared starting from initiators or terminating agents with long alkyl chains and hydrophilic 2-oxazoline $[8,9]$. Similar architectures were performed from perfluoro initiator [10]. Some examples of graft copolymers were also referred to poly(2-methyl-2- 
oxazoline) and phosphazene [11] or chitine [12]. The large demand for surfactants urgently calls for sustainable surfactants made from renewable raw materials to reduce the impact on the environment and to save fossil resources [13]. In this sense few nonionic polyoxazoline surfactants based on vegetable biomass have been synthesized from glycerol [14] and lipopolymers [15-18]. Schubert et al. have recently reported the synthesis of amphiphilic poly(2-ethyl-2-oxazoline-block-2-"soyalkyl"-2oxazoline) copolymers from soybean fatty acid $[19,20]$. The polyoxazoline block was synthesized using a new oxazoline monomer containing a C18 long unsaturated chain issued from soybean oil.

In this article, we described a new route to synthesize amphiphilic lipid-POx CO-POx $\mathbf{x}_{\mathbf{n}}$ copolymers using commercial castor oil CO backbone with various hydrophilic block lengths. Here, hydrophobic group was introduced at the initiation stage of polymerization of 2-methyl-2-oxazoline MOx ("initiator method") by a derivative of castor oil (COTs). The surface properties of these nonionic polymeric surfactants were also investigated as well as self-ordering of CO-POx $\mathbf{x}_{\mathbf{n}}$ in the solid state. 


\section{Experimental Part}

\section{Experimental Methods}

${ }^{1} \mathrm{H}$ NMR spectra $(\delta$, ppm) were recorded on a Bruker DRX $200 \mathrm{MHz}$ spectrometer with tetramethylsilane as internal standard. Chemical shifts are reported in ppm. Size exclusion chromatography (SEC) was performed on a Spectra-Physics apparatus equipped with an RI Shodex refractive index detector. Two PL-gel mix C columns were used at $70{ }^{\circ} \mathrm{C}$ with a $0.8 \mathrm{~mL} \cdot \mathrm{min}^{-1}$ flow rate of DMF $(0.1 \% \mathrm{LiBr})$, calibrated using polymethylmethacrylate standards. Contact angle measurements were performed on polymer films that were prepared from chloroform solutions. Solutions of copolymer (5/95 w./w.\% copolymer/ $\left.\mathrm{CHCl}_{3}\right)$ was deposited onto glass plates and solvent was evaporated in a vented oven. A G10 optical contact angle measuring instrument from Krüss was used to determine the contact angles of diodomethane as apolar test liquid. The drops of diodomethane were deposited on 3 different areas of the surface with a microsyringe. Results are mean value of three measurements on different parts of the samples. Polymers were analysed by Environmental Scanning Electron Microscope (ESEM) FEI QUANTA 200. The samples were examined without any preparation (samples placed directly onto ESEM stage). The ESEM was operated in low-vacuum mode, at a pressure of 2.87 Torr under a water vapour atmosphere. Others operational parameters were as follows: working distance $10 \mathrm{~mm}$, and operating voltage $15 \mathrm{kV}$. Elemental analyses (EDX) were realized under the same operational parameters as for imaging. During EDX analysis the elements were both qualitatively and quantitatively measured. The surface activity of the synthesized surfactant was determined using a Krüss digital tensiometer K 12 equipped with a platinum plate. The surface tension was measured by the Wilhelmy plate method. The solutions were transferred into a vessel that was thermostated by circulating water at the desired temperature $(298 \mathrm{~K})$. The accuracy of the measurements was $0.1 \mathrm{mN} / \mathrm{m}$. The minimum cross-section area of the surfactant head group, $\mathrm{a}_{0}$, was calculated according to equation (1): 


$$
\mathrm{a}_{0}=\frac{1}{\Gamma_{\mathrm{m}} \mathrm{N}_{\mathrm{A}}}
$$

where $\Gamma_{\mathrm{m}}$ is the maximum value of the surface excess concentration determined from the plot of $\gamma$ versus the logarithm of the surfactant concentration using the following Gibbs equation:

$$
\Gamma_{\mathrm{m}}=-\frac{1}{2.3 \mathrm{RT}} \cdot \lim _{\mathrm{c} \rightarrow \mathrm{cmc}} \frac{\mathrm{d} \gamma}{\mathrm{d}(\log \mathrm{C})}
$$

$\mathrm{N}_{\mathrm{A}}$ is the Avogadro number, $\mathrm{R}=8.32 \mathrm{~J} \cdot \mathrm{mol}^{-1} \cdot \mathrm{deg}^{-1}, \mathrm{~T}=298 \mathrm{~K}$ and $\gamma$ is expressed in N.m $\mathrm{m}^{-1}$.

The mean size of micelle was determined by Dynamic light scattering (DLS) using the autocorrelation function of the scattered light with a Malvern photon correlation spectrometer (Zetasizer 3000HS of Malvern Instruments, Malvern, UK). The measurements were carried out at a scattering angle $90^{\circ}$ and at constant temperature $\mathrm{T}=298.15 \mathrm{~K}$. Hydrophilic-Lipophilic Balance (HLB) values of CO-POx surfactants were calculated by the commonly used general formula for non-ionic ones:

$$
H L B=20 \frac{M_{H}}{M_{H}+M_{L}}
$$

where $\mathrm{M}_{\mathrm{H}}$ and $\mathrm{M}_{\mathrm{L}}$ are the molecular weights of the hydrophilic segment $\mathbf{P O} \mathbf{x}_{\mathbf{n}}$ and of the lipophilic segment CO of the CO-POx $\mathbf{x}_{\mathbf{n}}$ molecule, respectively.

\section{Experimental Section}

\section{Materials}

Diethyl ether, methanol, chloroform, Milli-Q water, p-toluenesulfonyle chloride (TsCl), castor oil (CO), $\mathrm{KOH}$ and $\mathrm{CaH}_{2}$ were purchased from ACROS and used as received. Pyridine was distilled from $\mathrm{KOH}$ under nitrogen. Acetonitrile was dried and distilled according to standard procedures [21]. 2Methyl-2-oxazoline (MOx) was dried and distilled from $\mathrm{CaH}_{2}$ and stored under a dry nitrogen atmosphere. Deuterated solvents were purchased from SDS and used without further purification. 


\section{Characterization of castor oil: CO}

Castor oil (CO) is used as received and its composition is the following [ricinoleic ester (90\%), oleic ester (4\%), linoleic ester (1\%), linolenic ester (1\%), stearic ester (1\%), palmitic ester (1\%), dihydroxystearic ester (1\%) and others (1\%)].

${ }^{1} \mathrm{H}$ NMR $\left(\mathrm{CDCl}_{3}\right) \quad \delta 5.6$ and $5.4\left(\mathrm{~m}, \mathrm{H}_{\mathrm{j}}\right), 5.25\left(\mathrm{~m}, \mathrm{H}_{\mathrm{i}}\right), 4.3$ and $4.15(\mathrm{dd}, J=11.9 \mathrm{~Hz}$ and $J=4.2 \mathrm{~Hz}$, $\left.\mathrm{H}_{\mathrm{h}}\right), 3.6\left(\mathrm{~m}, \mathrm{H}_{\mathrm{g}}\right), 2.3\left(\mathrm{t}, J=7.4 \mathrm{~Hz}, \mathrm{H}_{\mathrm{e}}\right), 2.2\left(\mathrm{t}, J=7.4 \mathrm{~Hz}, \mathrm{H}_{\mathrm{d}}\right), 2.05\left(\mathrm{~m}, \mathrm{H}_{\mathrm{c}}\right), 1.7-1.2\left(\mathrm{~m}, \mathrm{H}_{\mathrm{b}}\right), 0.85\left(\mathrm{~s}, \mathrm{H}_{\mathrm{a}}\right)$.

${ }^{13} \mathrm{C} \mathrm{NMR}\left(\mathrm{CDCl}_{3}\right) \quad \delta 173.2$ and $172.8(\mathrm{C}=\mathrm{O}), 133.1$ and $125.5\left(\mathrm{C}_{\mathrm{j}}\right), 71.5\left(\mathrm{C}_{\mathrm{g}}\right), 68.8\left(\mathrm{C}_{\mathrm{i}}\right), 62.6\left(\mathrm{C}_{\mathrm{h}}\right)$, 36.8-22.3 (others carbons), $14.0\left(\mathrm{C}_{\mathrm{a}}\right)$.

\section{Synthesis of vegetable oil macroitiator: COTs}

A flask equipped with an addition funnel was charged with CO $(5.61 \mathrm{~g})$ and pyridine $(2.0 \mathrm{~mL})$ dissolved in chloroform $(0.5 \mathrm{M}, 13 \mathrm{~mL})$. A solution of $\mathrm{TsCl}(1.33 \mathrm{~g}, 1.15$ eq. in respect to $1 / 3$ of total $\mathrm{OH}$ groups of CO) in $42 \mathrm{ml}$ of chloroform was added dropwise under nitrogen atmosphere. After the addition of $\mathrm{TsCl}$, the reactional mixture was stirred for $3.5 \mathrm{~h}$ at room temperature. The organic layer was washed with diluted $\mathrm{CuSO}_{4}$ solution $\left(10 \mathrm{~g} . \mathrm{L}^{-1}\right)$, dried $\left(\mathrm{Na}_{2} \mathrm{SO}_{4}\right)$ and concentrated to give COTs. COTs was obtained with a yield close to $70 \%$. OH conversion rate are detailed in the following part.

${ }^{1} \mathrm{H}$ NMR $\left(\mathrm{CDCl}_{3}\right) \quad \delta 7.75\left(\mathrm{~d}, J=7.5 \mathrm{~Hz}, \mathrm{H}_{\mathrm{l}}\right), 7.3\left(\mathrm{~d}, J=7.5 \mathrm{~Hz}, \mathrm{H}_{\mathrm{k}}\right), 5.6$ and $5.4\left(\mathrm{~m}, \mathrm{H}_{\mathrm{j}}\right), 5.25\left(\mathrm{~m}, \mathrm{H}_{\mathrm{i}}\right)$, $4.5\left(\mathrm{~m}, \mathrm{H}_{\mathrm{g}}\right), 4.3-4.15\left(\mathrm{~m}, \mathrm{H}_{\mathrm{h}}\right), 3.6\left(\mathrm{~m}, \mathrm{H}_{\mathrm{g}}\right), 2.4\left(\mathrm{~s}, \mathrm{H}_{\mathrm{f}}\right), 2.3\left(\mathrm{t}, J=7.4 \mathrm{~Hz}, \mathrm{H}_{\mathrm{e}}\right), 2.2\left(\mathrm{t}, J=7.4 \mathrm{~Hz}, \mathrm{H}_{\mathrm{d}}\right), 2.1-$ $1.85\left(\mathrm{~m}, \mathrm{H}_{\mathrm{c}}\right), 1.7-1.1\left(\mathrm{~m}, \mathrm{H}_{\mathrm{b}}\right), 0.8\left(\mathrm{~m}, \mathrm{H}_{\mathrm{a}}\right)$.

${ }^{13} \mathrm{C}$ NMR $\left(\mathrm{CDCl}_{3}\right) \quad \delta 173.2$ and $172.8(\mathrm{C}=\mathrm{O}), 144.9\left(\mathrm{C}_{\text {aromatic }}\right), 134.6\left(\mathrm{C}_{\text {aromatic }}\right), 133.0\left(\mathrm{C}_{\mathrm{j}}\right), 129.9$ $\left(\mathrm{C}_{\text {aromatic }}\right), 127.7\left(\mathrm{C}_{\text {aromatic }}\right), 125.3\left(\mathrm{C}_{\mathrm{j}}\right), 71.4\left(\mathrm{C}_{\mathrm{g}}\right), 68.8\left(\mathrm{C}_{\mathrm{i}}\right), 66.7\left(\mathrm{C}_{\mathrm{g}}\right)$ ), $62.0\left(\mathrm{C}_{\mathrm{h}}\right)$, 36.8-21.2 (others carbons), 14.6 ( $\mathrm{C}_{\mathrm{a}}$ with Ts group), 14.0 ( $\mathrm{C}_{\mathrm{a}}$ without modification $)$. 


\section{Typical polymerization of MOx from COTs: CO-POx}

All reactions were carried out under a dry nitrogen atmosphere. COTs and MOx were dissolved in dry acetonitrile $(4 \mathrm{M})$. The solution was vigourously stirred at $80^{\circ} \mathrm{C}$ for 2 days. The reaction product was quenched by addition of an adequate amount of methanolic $\mathrm{KOH}(10 \mathrm{eq})$. The flask was kept $4 \mathrm{~h}$ at $30^{\circ} \mathrm{C}$. After cooling,) and dried overnight in vacuum as a pale yellow viscous solid.

The copolymer was isolated by slow precipitation from cold diethyl ether (where the non functionalized CO remained soluble

${ }^{1} \mathrm{H}$ NMR $\left(\mathrm{CDCl}_{3}\right) \quad \delta \mathrm{H}_{\mathrm{g}}, \mathrm{H}_{\mathrm{h}}, \mathrm{H}_{\mathrm{i}}, \mathrm{H}_{\mathrm{j}}$ are not visible, 3.6-3.3 (m, $\mathrm{CH}_{2}-\mathrm{CH}_{2} \mathbf{P O x}$ and $\left.\mathrm{H}_{\mathrm{g}}\right), 2.3-2.0(\mathrm{~m}$, $\mathrm{H}_{\mathrm{c}}, \mathrm{H}_{\mathrm{d}}, \mathrm{H}_{\mathrm{e}}$ and $\mathrm{CH}_{3}$ POx $), 1.7-1.2\left(\mathrm{~m}, \mathrm{H}_{\mathrm{b}}\right), 0.85\left(\mathrm{~m}, \mathrm{H}_{\mathrm{a}}\right)$.

${ }^{13} \mathrm{C}$ NMR $\left(\mathrm{CDCl}_{3}\right) \quad \delta 181.2(\mathrm{C}=\mathrm{O}$ POx$), 172.6(\mathrm{C}=\mathrm{O}$ CO $), \mathrm{C}_{\mathrm{j}}$ no visible, $71.0\left(\mathrm{C}_{\mathrm{g}}\right), \mathrm{C}_{\mathrm{h}}$ and $\mathrm{C}_{\mathrm{i}}$ no visible, 49.3-43.8 ( $\mathrm{CH}_{2}$ POx), 32.5-20.6 (others carbons), $14.0\left(\mathrm{C}_{\mathrm{a}}\right)$. 


\section{Results and discussion}

\section{Synthesis of lipid-macroinitiator COTs}

The polymerization of oxazoline was investigated using a lipid based macroinitiator. Castor oil $\mathbf{C O}$ is unique among all oils since it is the only one containing about $90 \%$ of $\mathrm{C}_{18}$ hydroxylated fatty acid ricinoleic acid (12-Hydroxyoleic Acid) which is interesting for further chemical modifications. Its peculiar structure combines one unsaturation with one hydroxyl functions on the same molecule (Scheme 1) [22-26]. Thus, castor Soil CO can act as macroinitiator after chemical modification of the OH groups. Herein, hydroxyl group was converted into tosylate initiator COTs. On order to obtain compounds bearing surfactant properties with a correct HLB balance, only one OH group of the three ones per triglyceride molecule was modified (Scheme 1). This compound was obtained in one step under mild conditions from $\mathbf{C O}$ and $\mathrm{TsCl}$ (ratio $\mathrm{TsCl} / \mathrm{OH}=1.15$ ). The chemical modification was checked by ${ }^{1} \mathrm{H}$ NMR analysis. COTs spectrum revealed typical signals of vegetable castor oil CO as can be seen in Figure 1. Protons of unsaturated alkene group were observed as a multiplet at 5.6 and 5.4 ppm. Methylene and methine groups of glycerol part appeared at 4.3-4.15 and 5.25 ppm, respectively. Methine groups bearing alcohol oxygen atom were observed at $3.6 \mathrm{ppm}$. Methylene groups in $\alpha$ position of alkene or of carbonyl ester appeared at 2.3-2.05 ppm. Terminal methyl group of ricinoleate was detected as a peak at $0.85 \mathrm{ppm}$. The presence of tosylate group was verified, since the aromatic protons and the methine group bearing an oxygen atom appeared respectively at 7.75-7.3 and $4.5 \mathrm{ppm}$. Moreover the chemical modification of castor oil CO with tosylate group was proved by ${ }^{13} \mathrm{C}$ NMR analysis with the appareance of aromatic carbons around $130 \mathrm{ppm}$. Finally, the calculations confirmed that one of the three alcohol groups of castor oil CO was transformed in COTs taking into account that unmodified oil was eliminated during the purification step. 


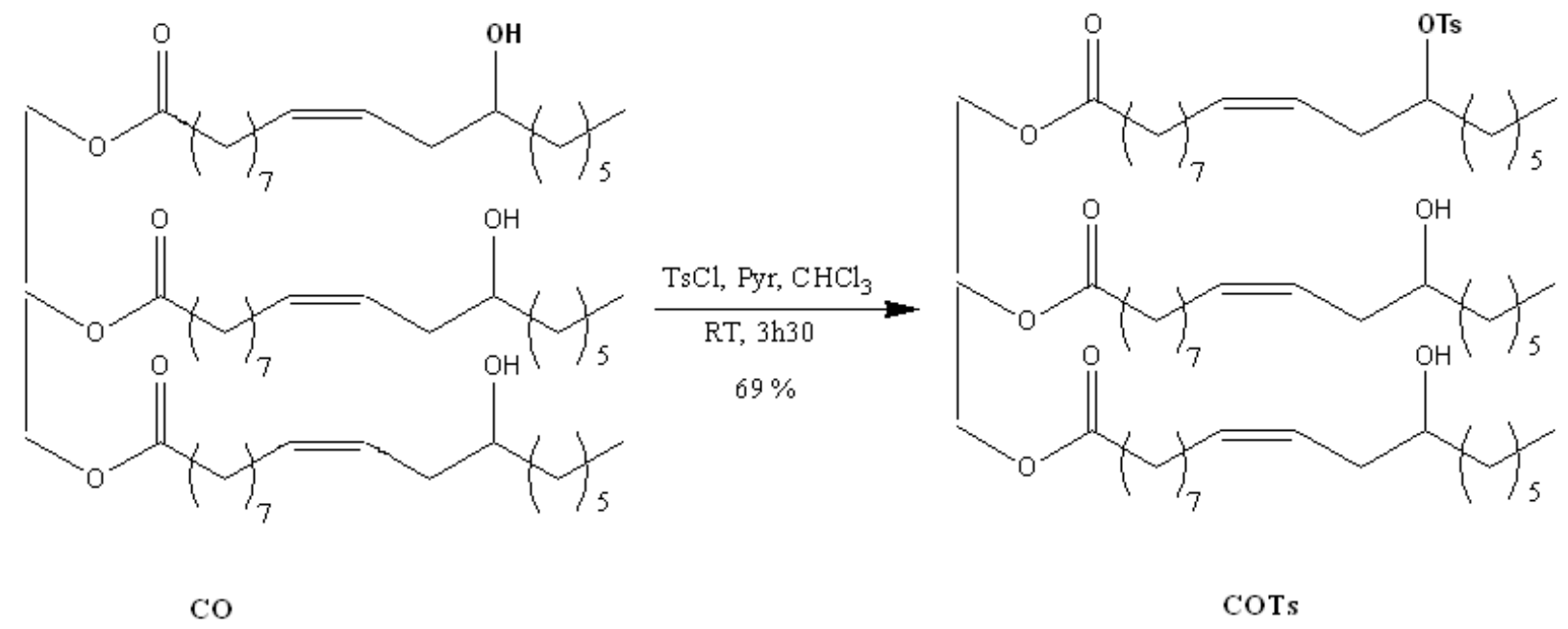

Scheme 1: Synthesis of vegetable oil macroinitiator COTs.

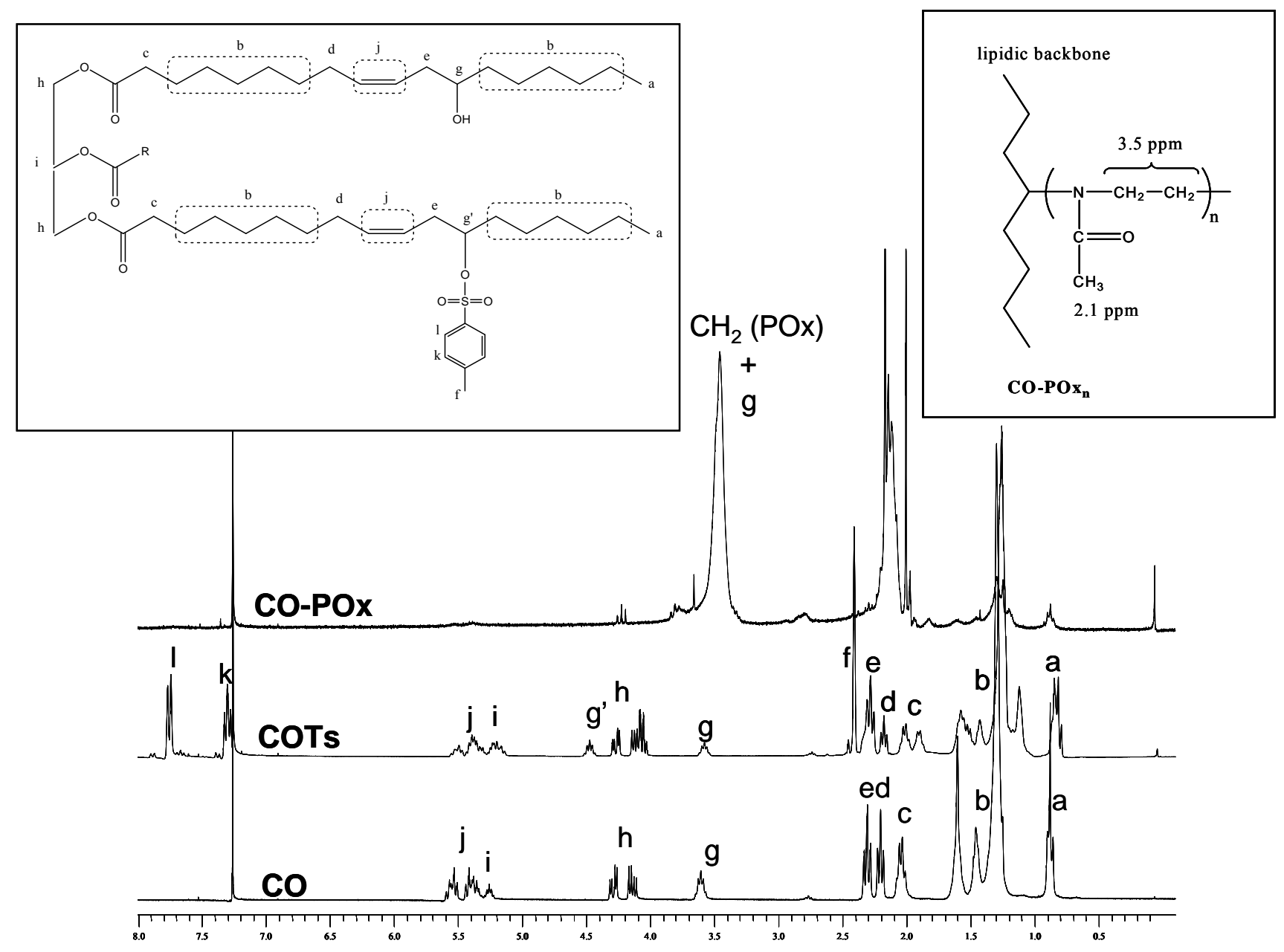

Figure 1. ${ }^{1} \mathrm{H}$ NMR spectra $\left(\mathrm{CDCl}_{3}\right.$ solution) of $\mathbf{C O}, \mathbf{C O T s}$ and $\mathbf{C O}-\mathbf{P O x}_{\mathbf{n}}(\mathrm{R}=$ unreactive fatty acid chain). 


\section{Polymerization of MOx based on COTs initiator}

The polymerization of MOx was achieved using lipophilic macroinitiator COTs in refluxing acetonitrile for 2 days as shown in Scheme 2. The polymerization was terminated by adding a large excess of a $\mathrm{KOH}$ saturated methanolic solution and was kept at $30^{\circ} \mathrm{C}$ during $4 \mathrm{~h}$. The copolymer was purified by slow precipitation from cold diethyl ether where the non copolymerized COTs remained soluble.

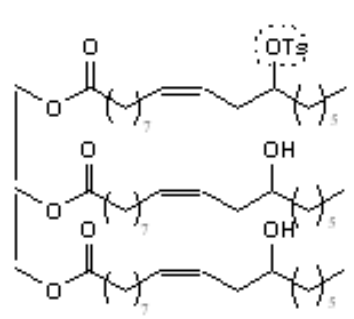

COTs

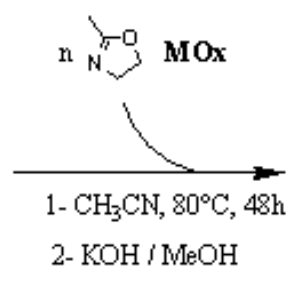

$2-\mathrm{KOH} / \mathrm{MeOH}$

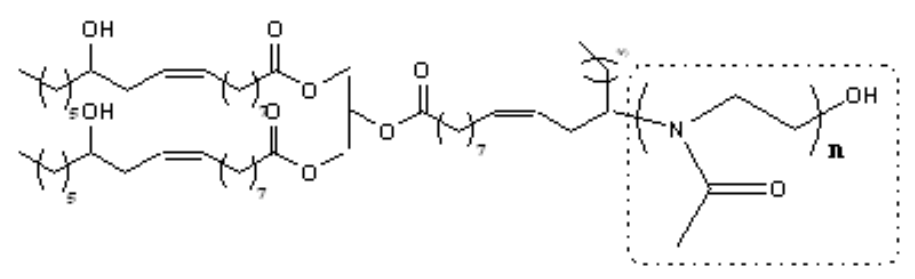

$\operatorname{COPOx}_{\mathrm{n}}$

Scheme 2: Polymerization of MOx based on lipidic macroinitiator COTs.

The experimental number-average molecular weights measured by GPC analysis were smaller than the theoretical ones in the most of the cases. The narrow polydispersity were also obtained from GPC and ranged from 1.06 to 1.12 as summarized in Table 1 . Until $\overline{D P_{n}}$ of 10 , the experimental values were consistent with the theoretical ones (Figure 2). For higher molecular weights, the experimental values deviated from the theoretical ones and should be explained by a decrease of initiator efficiency. In addition, the molecular weight versus conversion plot linearly increased with the conversion plot $\left(\overline{D P_{n}^{\text {th }}}\right.$ $=20$ ), as shown in Figure 3. The experimental values were lower than the theoretical ones and the shift between them might be related to the used PMMA calibration.

Table 1: Polymerization of MOx using COTs as initiator. 


\begin{tabular}{ccccc}
\hline & $\overline{D P_{n}^{\text {theo }}}$ & $\overline{D P_{n}^{G P C}} *$ & $\overline{M n_{n}^{G P C}}\left({\left.\mathrm{~g} \cdot \mathrm{mol}^{-1}\right)}^{*}\right.$ & $\overline{M_{w}} / \overline{M_{n}} *$ \\
\hline CO-POx $_{5}$ & 5 & 5.0 & 1354 & $1.0_{6}$ \\
CO-POx $_{9.3}$ & 10 & 9.3 & 1723 & $1.1_{0}$ \\
CO-POx $_{10.3}$ & 15 & 10.3 & 1810 & $1.1_{2}$ \\
CO-POx $_{15.2}$ & 20 & 15.2 & 2223 & $1.1_{2}$ \\
\hline
\end{tabular}

*: Estimated by GPC in DMF based on PMMA standards.

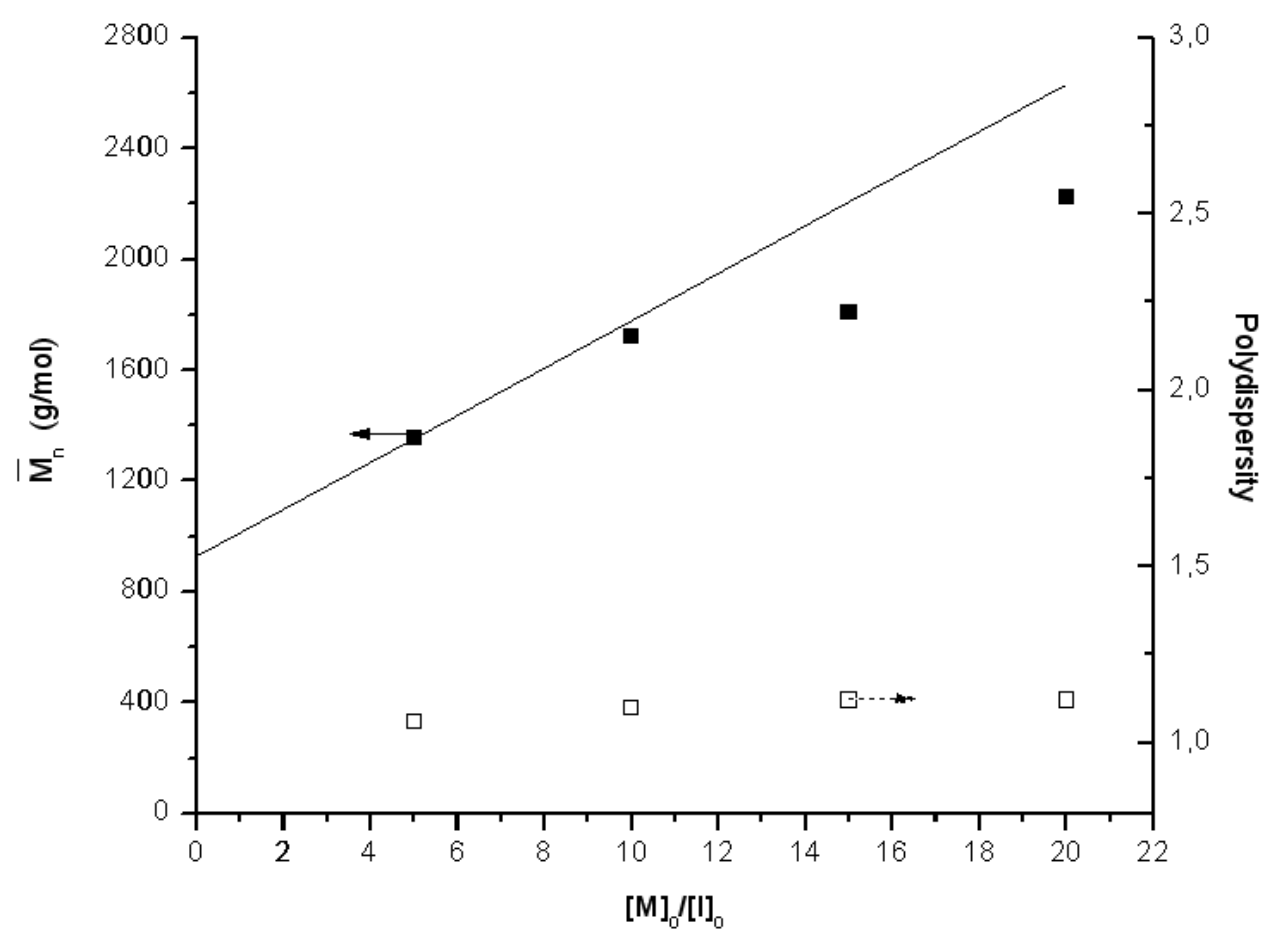

Figure 2: $\overline{M_{n}}$ and polydispersity obtained by means of GPC for MOx initiated by COTs. 


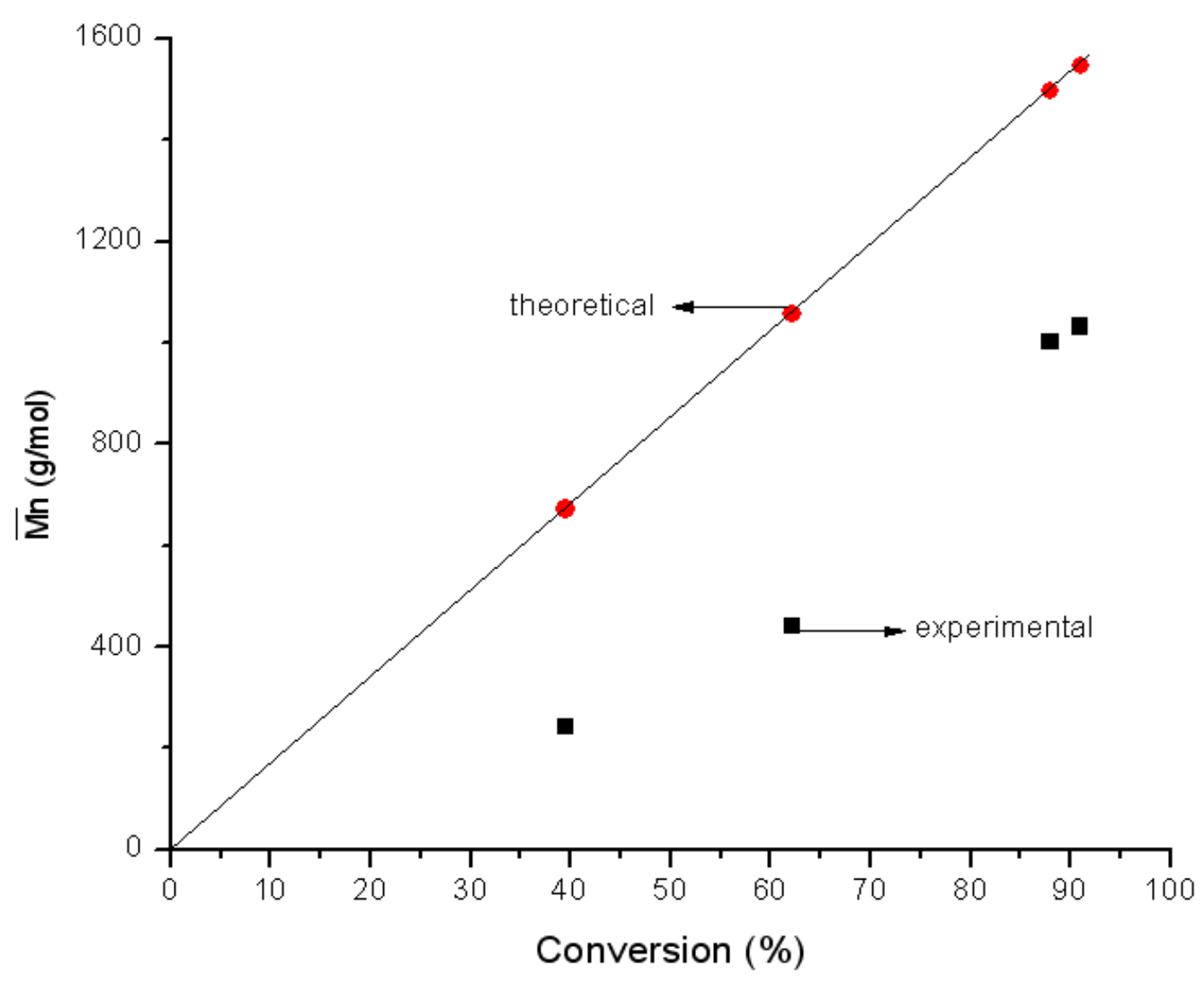

Figure 3: $\overline{M_{n}}$ versus monomer conversion for the polymerization of MOx initiated by COTs $\left(\overline{D P_{n}^{\text {theo }}}\right.$ =20).

Various lengths of hydrophilic block were synthesized to evaluate the influence of the HydrophilicLipophilic Balance, or HLB, on interfacing properties. This parameter was determined using the general formula applied for nonionic surfactants taking into account the weight fractions of the hydrophilic and of the lipophilic portions of the molecule (see experimental part) [27]. The approximative HLB values calculated for CO-POx 6 , CO-POx 9.3 and CO-POx 15.2 ranged from 7 to 9.2 , these values being close to that of usual hydrophilic surfactants.

The proof of the grafting of POx segment onto the lipid backbone throught a initiator COTs was also evaluated by the study of surface properties of the CO-POx $\mathbf{x}_{\mathbf{n}}$ compared to COTs films by measuring the contact angle of diodomethane drops onto the surface of the films. A remarkable difference existed between CO-POx $\mathbf{x}_{\mathbf{n}}$ and COTs contact angles with $50^{\circ}$ and $15^{\circ}$ respectively. This means logically that 
hydrophilicity of CO-POx $\mathbf{x}_{\mathbf{n}}$ increased in comparison to COTs precursor one and proved the grafting of POx onto lipid macroinitiator.

\section{Self-assembly of $\mathrm{CO}-\mathrm{PO}_{\mathrm{n}}$ in aqueous solution}

The surface activity of $\mathbf{C O}-\mathbf{P O} \mathbf{x}_{6}$ and $\mathbf{C O}-\mathbf{P O}_{9.3}$ were characterized using surface tension measurements. Figure 4 displays the surface tension versus the logarithm of the concentration for CO$\mathbf{P O x}_{6}$ and $\mathbf{C O}-\mathbf{P O}_{9.3}$ aqueous solutions. The decrease in surface tension with increasing concentration is typical of surface active molecules [27]. This behaviour is explained by the spontaneous adsorption of the amphiphilic molecules from the solution to the solution/air interface. Above the critical micellar concentration, or $\mathrm{CMC}$, there is no longer any change in the surface tension of the solution as the water/air interface becomes saturated. The curves show sharp break enough to allow the accurate evaluation of the $\mathrm{CMC}$, which is taken as the concentration at the intersection of the two linear portions of the $\gamma=\mathrm{f}(\log \mathrm{C})$ plots, where $\gamma$ and $\mathrm{c}$ are the surface tension and the concentration of the solution, respectively.

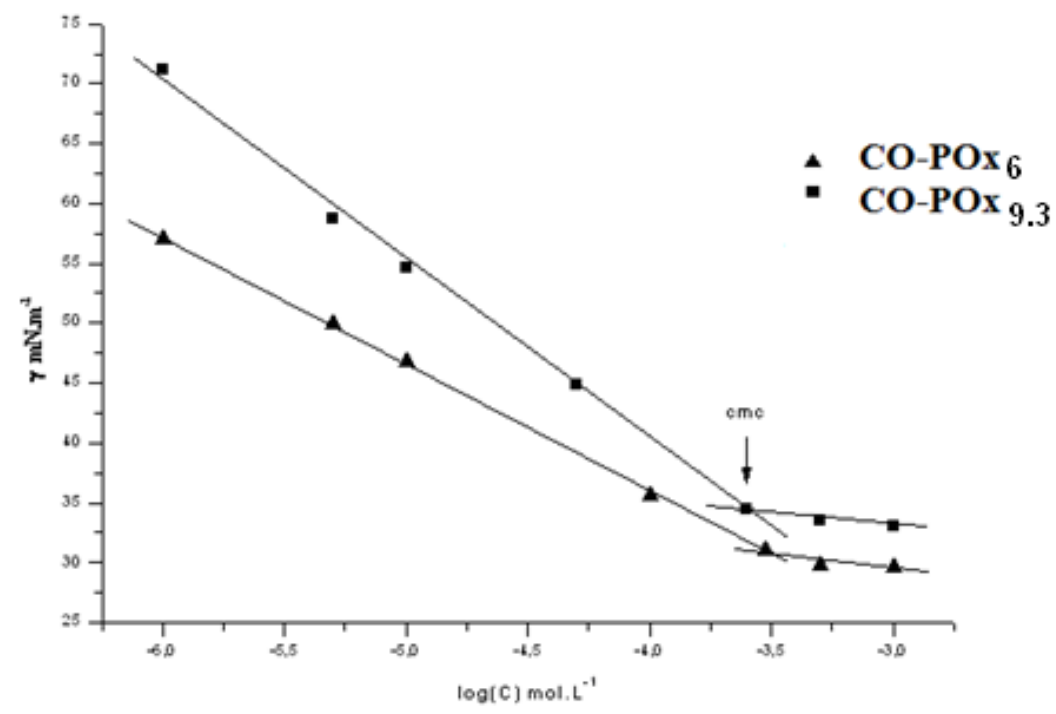

Figure 4: Change in surface tension with log concentration of CO-POx $\mathbf{x}_{6}$ and CO-POx $\mathbf{x}_{9.3}$ at $298 \mathrm{~K}$. 
Table 2 lists the values obtained from these plots, $\mathrm{CMC}, \Gamma_{\mathrm{m}}$ (maximum value of the surface excess concentration) and $\mathrm{a}_{0}$ (minimum head group surface area). The experimental values of CMC of CO$\mathbf{P O x}_{6}$ and $\mathbf{C O}-\mathbf{P O}_{9.3}$ were consistent with those of typical nonionic surfactants which were around $10^{-4}$ mol.L $\mathrm{L}^{-1}$. CO-POx 6 and CO-PO ${ }_{9.3}$ also show a surface tension of 34.5 and $30.0 \mathrm{mN} . \mathrm{m}^{-1}$, respectively. Additionally CO-POx 6 exhibits a value of the cross-sectional area of $63 \AA^{2}$ while for CO-PO $\mathbf{C O}_{9.3}$ the value is $88 \AA^{2}$. The chemical nature, structure and length of the polyoxazoline hydrophilic block were essential in determining the surfactant behaviour in solution. Lengthening the polyoxazoline segment in the polar head group results in an increase of the $\mathrm{CMC}$ value and in its cross-section at the liquid-gas interface. This behaviour was consistent with the increase in the hydrophilic character of the surfactant molecules, which prevents the micellization. Indeed, the hydration of the headgroup and consequently the degree of repulsive interactions increase with the number of polyoxazoline units. Moreover, the corresponding values of the head group surface area (Table 2) were closed to those of usual surfactant molecules with two hydrocarbon chains [17]. This suggests that the polyoxyazoline group exhibits an extended conformation and penetrates into the water phase as it was characterized from X-ray reflectometry for a polyoxazoline lipopolymer CO-POx $\mathbf{x}_{\mathbf{n}}[28]$.

Table 2. CMC values, maximum values of the surface excess concentration and surfactant head group surface area $\left(a_{0}\right)$.

\begin{tabular}{|c|c|c|c|c|c|}
\hline & $\gamma_{\text {CMC }}$ & $\mathrm{CMC}$ & HLB & $\Gamma \max$ & $\begin{array}{c}\text { Head group } \\
\text { surface area }\left(a_{0}\right)\end{array}$ \\
\hline & $\mathbf{m N} \cdot \mathrm{m}^{-1}$ & mol.L ${ }^{-1}$ & & $\mu \mathrm{mol} . \mathrm{m}^{-2}$ & $\AA^{2}$ \\
\hline $\mathrm{CO}^{-\mathrm{POx}_{6}}$ & 34.5 & $2.510^{-4}$ & 7 & 2.65 & 63 \\
\hline CO-POX ${ }_{9.3}$ & 30.0 & $3.010^{-4}$ & 9.2 & 1.88 & 88 \\
\hline
\end{tabular}


DLS measurements indicate that polyoxazoline surfactants $\mathbf{C O}-\mathbf{P O} \mathbf{x}_{\mathbf{n}}$ have a very strong propensity to form giant micelles or aggregates (Figure 5). The average size of aggregates observed in aqueous solution was about $200-300 \mathrm{~nm}$ with a large size distribution. The relatively high diameter, $300 \mathrm{~nm}$, of these structures suggests the formation of vesicles or nonspherical micelles. Further research is currently being carried out to determine the structure and the morphology of these polyoxyazoline surfactant micelles.

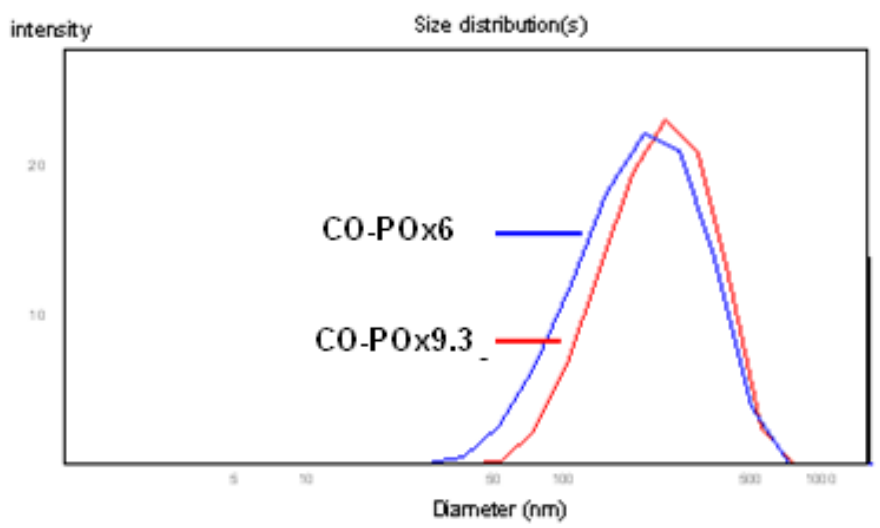

Figure 5: Distribution of hydrodynamic radius (Rh) for CO-POx $\mathbf{x}_{6}$ and $\mathbf{C O}-\mathbf{P O} \mathbf{x}_{9.3}$ at $298 \mathrm{~K}$.

\section{Cooperative organization of $\mathrm{CO}-\mathrm{PO}_{\mathrm{n}}$ in solid state}

To determine the organization in the bulk and identify the ordered nanopattern of CO-POx $\mathbf{x}_{\mathbf{n}}$ the segregation of lipophilic and polyoxazoline parts was studied by evaporation from concentrated aqueous solution as previously mentioned in the case of poly(2-oxazoline) multiblock copolymers deposited onto surfaces $[29,30]$. The nanopatterns result from the precipitation of one part of amphiphilic surfactant. The evaporated solvent and the limit of solubility of the less soluble part induced its precipitation and the formation of nanopatterns since the other part remains still soluble. In our case environmental scanning electron microscopy (ESEM) and energy dispersive X-ray (EDX) analysis were used. During ESEM analysis the pressure in the chamber of the microscope slowly rised to avoid any degradation and 
let gradual evaporation of water contained in the sample. In a first step, $\mathbf{C O}-\mathbf{P O}_{\mathbf{9 . 3}}$ sample was analysed after spraying water at the surface to favor the self-organization. A variety of ESEM images of the CO$\mathbf{P O}_{9.3}$ were taken and one of them is shown in Figure 6. Under a pressure of 0.87 torr, no pattern appeared on the surface of the sample while under 2.87 torr some star-shaped morphologies with numerous stripes distributed in the radial direction were observed. The number and the length of stripes per star-shaped morphology varied as well as the size of the patterns ranged from 50 to $200 \mu \mathrm{m}$. Starshaped patterns were spontaneously generated by drying under pressure and illustrate the influence of the evaporation in the cooperative organization in the bulk.

By EDX analysis, nitrogen elemental percentage was quantified and gave information about the spatial distribution of POx in the sample because only polyoxazoline unit contains nitrogen atom in the surfactant structure. Compared to nitrogen elemental percentage in EDX analysis, the value measured in arms was up to 6 folder higher than matrix one. Thus the hydrophilic POx block was mainly isolated in the concentric surface stripes (black zone) and of course the fatty acid chains were localized in the matrix.
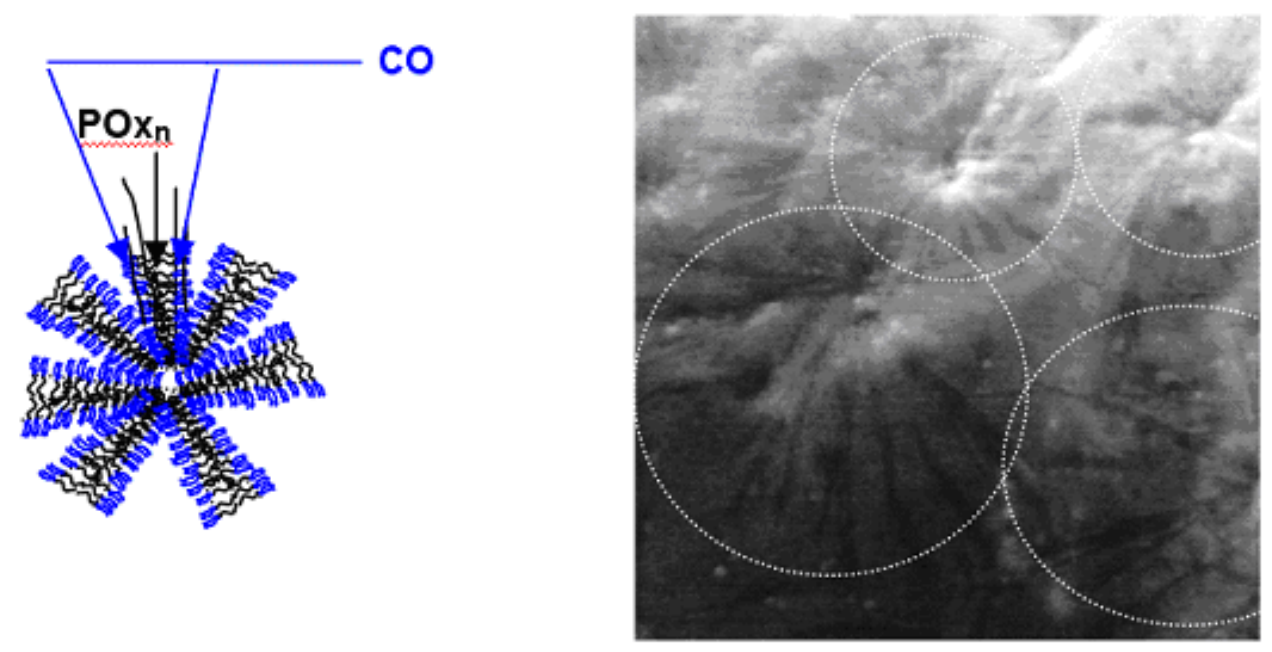

Figure 6: ESEM images of CO-POx $\mathbf{x}_{9.3}$ in solid state. 


\section{Conclusions}

Nonionic polymer surfactants $\mathbf{C O}-\mathbf{P O X} \mathbf{X}_{\mathbf{n}}$ based on vegetable oil (castor oil) $\mathbf{C O}$ and poly(2-methyl-2oxazoline) were synthesized with narrow polydispersity. From GPC study, the low molecular weights were consistent with theoretical values whereas a deviation appeared to the higher molecular weights.. The hydrophilic-lipophilic balance of the $\mathbf{C O}^{-} \mathbf{P O X}_{\mathbf{n}}$ surfactants and their surface tension values correspond to those of usual nonionic surfactants. Thus the influence of surfactant HLB on the CMC was confirmed with higher values of CMC for longer polyoxazoline hydrophilic chains. The average size of aggregates of these structures suggests the formation of vesicles or nonspherical micelles. The cooperative organization by precipitation of $\mathbf{C O}^{-\mathbf{P O X}_{\mathbf{n}}}$ was also shown in solid state with ESEM-EDX analysis which revealed a star-shaped morphologies where polyoxazoline POx was mainly localized in stripes.

\section{ACKNOWLEDGMENT}

The authors thank Dr. C. Grill for technical assistance with ESEM-EDX analysis. 


\section{REFERENCES}

1. T.M. Baber, D.T. Vu, C.T. Lira, Journal of Chemical and Engineering Data 47(6) (2002) 1502.

2. M.C. Woodle, C.M. Engbers, S. Zalipsky, Bioconjugate Chemistry 5(6) (1994) 493.

3. S. Kobayashi, Prog. Polym. Sci. 15 (1990), 751.

4. S. Kobayashi, T. Igarashi, Y. Moriuchi, T. Saegusa, Macromolecules 19(3) (1986) 535.

5. S. Takatsuka, T. Morita, Y. Horikiri, H. Yamahara, H. Saji, International Journal of Pharmaceutics 349(1-2) (2008) 94.

6. M.W.M. Fijten, J.M. Kranenburg, H.M.L. Thijs, R.M. Paulus, B.M. Van Lankvelt, J. De Hullu, M. Springintveld, D.J.G. Thielen, C.A. Tweedie, R. Hoogenboom, K.J. Van Vliet, U.S. Schubert, Macromolecules 40 (2007) 5879.

7. T.B. Bonne, K. Ludtke, R. Jordan, C.M. Papadakis, Macromolecular Chemistry and Physics 208(13) (2007) 1402.

8. S. Kobayashi, H. Uyama, Macromolecules 24(19) (1991) 5473.

9. G. Volet, V. Chanthavong, W. Wintgens, C. Amiel, Macromolecules 38(12) (2005) 5190.

10. R. Weberskirch, J. Preuschen, H.W. Spiess, O. Nuyken, Macromolecular Chemistry and Physics 201(10) (2000) 995.

11. J.Y. Chang, P.J. Park, M.J. Han, Macromolecules 33(2) (2000) 321.

12. K. Aoi, A. Takasu, M. Okada, T. Imae, Macromolecular Chemistry and Physics 200(5) (1999) 1112.

13. I. Johansson, M. Svensson, Current Opinion in Colloid \& Interface Science 6(2) (2001) 178.

14. M. Einzmann, W.H. Binder, Journal of Polymer Science Part a-Polymer Chemistry 39(16) (2001) 2821 .

15. T.R. Baekmark, T. Wiesenthal, P. Kuhn, A. Albersdorfer, O. Nuyken, R. Merkel, Langmuir $15(10)(1999) 3616$. 
16. T.R. Baekmark, T. Wiesenthal, P. Kuhn, T.M. Bayerl, O. Nuyken, R. Merkel, Langmuir 13(21) (1997) 5521.

17. A. Wurlitzer, E. Politsch, S. Huebner, P. Kruger, M. Weygand, K. Kjaer, P. Hommes, O. Nuyken, G. Cevc, M. Losche, Macromolecules 34(5) (2001) 1334.

18. O. Purrucker, A. Fortig, R. Jordan, M. Tanaka, Chemphyschem 5(3) (2004) 327.

19. H.Y. Huang, R. Hoogenboom, M.A.M. Leenen, P. Guillet, A.M. Jonas, U.S. Schubert, J.F. Gohy, Journal of the American Chemical Society 128(11) (2006) 3784.

20. R. Hoogenboom, Macromolecular Chemistry and Physics 208(1) (2007) 18.

21. D. Perrin. Purification of laboratory cgemicals. New york: Pergamon press, 1980.

22. K. Hill, Pure and Applied Chemistry 72(7) (2000) 1255.

23. Z.S. Petrovic, W. Zhang, I. Javni, Biomacromolecules 6(2) (2005) 713.

24. F.E. Okieimen, C. Pavithran, I.O. Bakare, European Journal of Lipid Science and Technology 107(5) (2005) 330.

25. T. Eren, S.H. Kusefoglu, Journal of Applied Polymer Science 91(6) (2004) 4037.

26. Z.S. Petrovic, A. Guo, W. Zhang, Journal of Polymer Science Part a-Polymer Chemistry 38(22) (2000) 4062.

27. M. Rosen. In: Inter-Science W, editor, 2004.

28. A. Wurlitzer, E. Politsch, G. Cevc, T. Gutberlet, K. Kjaer, M. Losche, Physica B-Condensed Matter 276 (2000) 343.

29. C.A. Fustin, H.Y. Huang, R. Hoogenboom, F. Wiesbrock, A.M. Jonas, U.S. Schubert, J.F. Gohy, Soft Matter 3(1) (2007) 79.

30. C.A. Fustin, V. Lefevre, R. Hoogenboom, U.S. Schubert, J.F. Gohy, Macromolecular Chemistry and Physics 208 (2007) 2026. 